\title{
Modelling spatial anisotropy of gold concentration data using GIS-based interpolated maps and variogram analysis: Implications for structural control of mineralization
}

\author{
Abani R Samal ${ }^{1,3, *}$, Raja R Sengupta ${ }^{2, * *}$ and Richard H Fifarek ${ }^{1, \dagger}$ \\ ${ }^{1}$ Department of Geology, Southern Illinois University, Carbondale, IL 62901-4324, USA. \\ ${ }^{2}$ Department of Geography, McGill University, 805 Sherbrooke St. W, Montreal, QC H3A 2K6, Canada. \\ ${ }^{3}$ Present address: 9063 West Phillips Drive, Littleton, CO 80128, USA. \\ *e-mail: arsamal@yahoo.com \\ **e-mail: sengupta@geog.mcgill.ca \\ †e-mail: fifarek@geo.siu.edu
}

Linear trends of anomalously high gold values in the Florida Canyon gold deposit, Nevada have been identified using a combination of contour maps of gold $\mathrm{(Au}$ ) concentration developed with a geographic information system (GIS) and variogram maps created using a geostatistical analysis package. These linear trends are interpreted to represent major fault zones that exerted a prinicipal control on gold mineralization and therefore imparted a spatial anisotropy to gold concentrations.

Oxidation state information such as oxide, sulfide or mixed was used initially to map and contour the lower limit of the oxidation zone. Linear trends on this surface suggest the location and trend of major structural elements in the deposit that guided late oxidizing fluids. Subsequently, four contour maps of gold concentrations in oxidized rocks were produced, each map representing $500 \mathrm{ft}$ vertical intervals starting at $3500 \mathrm{ft}$ above mean sea level (msl). Relatively high concentrations of $\mathrm{Au}$ that form linear trends on these maps suggest the presence of structural features, such as shear zones that controlled mineralization. Finally, to validate the observed trends, variogram maps of gold concentrations were derived through geostatistical analysis and the major axes of anisotropy were determined for each map.

The results that emerge suggest linear trends of northeast, northwest and, less prominently, northsouth orientations. The north-south and northeast trends match those of known and mapped major structures associated with the Florida Canyon deposit. However, the results imply a stronger control on mineralization by northwest-trending structures than previously recognized and the location of possible structures of all trends not previously mapped. They also serve to identify faults that controlled both early hydrothermal fluids and late oxidizing fluids since the gold distribution represents the time integrated effects of both fluid events.

The linear trends derived by spatial analysis (contour maps, variogram maps) of geochemical data (i.e., gold concentration), combined with the results of the field observations prove to be advantageous in understanding the structural control of gold mineralization. Such spatial analyses of geochemical concentration data are particularly useful in the field of mineral exploration.

Keywords. Structural control; spatial anisotropy; variography; GIS. 


\section{Introduction}

The application of GIS in geochemical mapping is a common practice in the mineral exploration industry (Harris et al 1997; Turner 1997; Yager and Folger 2003). Typically, metal concentration values are interpolated to create maps of one particular metal of interest, which are used to delineate target areas for further exploration (McClenaghan et al 1997; Adams 2006). However, the application of these interpolated contour maps to identify structural metals controlling mineralization is not a common practice. This study exploits the fact that (i) the metal distribution in many deposits can be controlled by pre-existing or coeval structural features and (ii) metals can be re-mobilized due to post-mineralization events, such as oxidation, resulting in a redistribution of elements and the creation of dispersion patterns along structural elements. For example, the structural features controlling upwelling hydrothermal ore fluids can also provide the channel way for downward percolating oxidizing fluids that destroy sulfides, remobilize metals and generate an oxidized layer of rocks above sulfide protore.

The objective of this study is to identify structural controls on gold mineralization at the Florida Canyon gold deposit in Pershing County, Nevada (figure 1) by utilizing GIS-generated contour maps in conjunction with variogram information derived from geostatistical analysis. The $\mathrm{Au}$ concentration data of the available drill-holes are used for these purposes. The mineralogical log-data of the exploration drill holes are first used to map the lower surface of oxidation in the deposit. The mineralogical information include relative abundance of iron oxides representing dominantly oxide, sulfide or mixed zones. This surface demarcates the first occurrence of sulfides ('oxidation surface') in each drill hole and reflects the uneven downward penetration of oxidizing fluids. Linear irregularities on the oxidation surface are interpreted as possible faults or shear zones. These linear features are then compared with linear trends on contour maps of gold concentration at different depth intervals through the oxidized part of the deposit.

The GIS-generated contour maps are the colour coded maps where, different colours represent different grades of gold $(\mathrm{Au} \mathrm{g} / \mathrm{t})$. These maps can be used to identify location with occurrences of relatively high concentrations of gold relative to the sorrounding areas. Variogram maps are unique tools that can identify and indicate the spatial anisotropy and autocorrelation of geochemical datasets. Higher spatial autocorrelations for longer distances along certain directions indicate a relatively greater spatial anisotropy along these

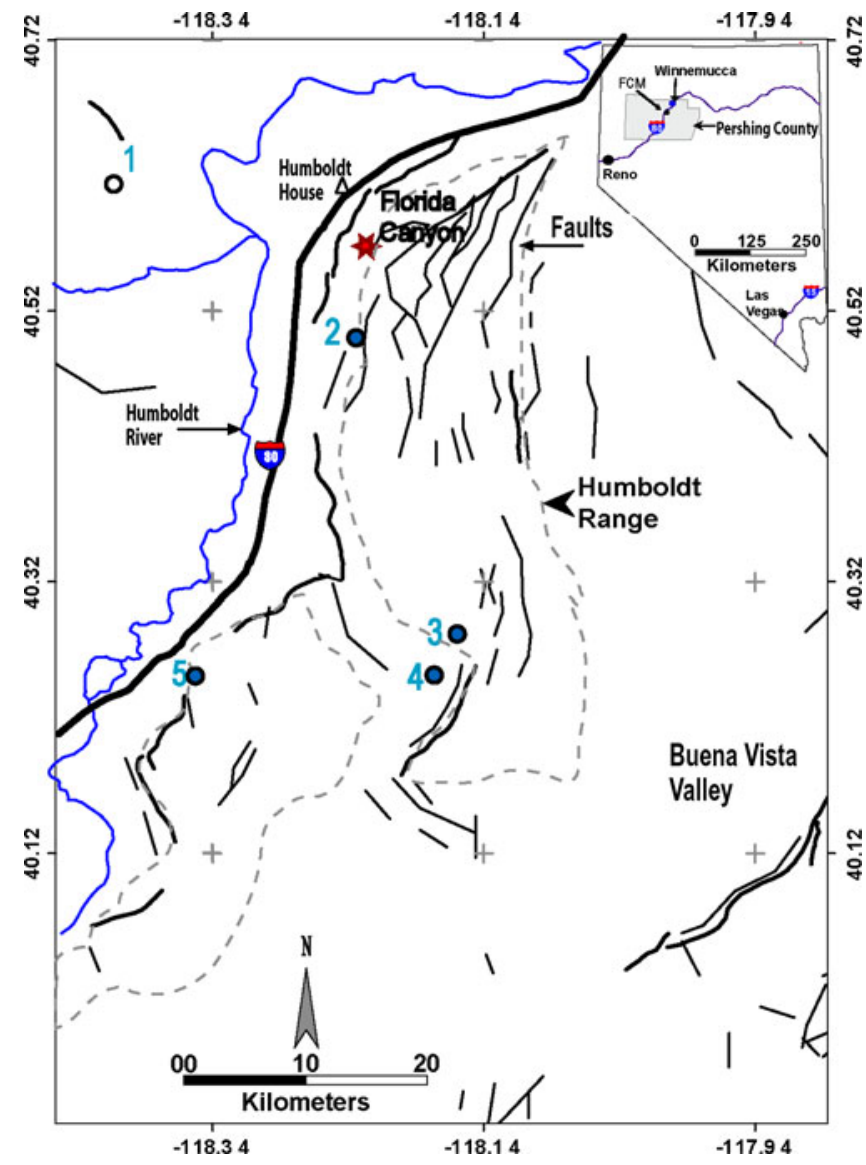

Figure 1. Location of Florida Canyon gold deposit in Humboldt Range, Pershing County, Nevada. Other known mineral deposits in and near the Humboldt Range are Majuba Placers (1), Standard mine (2), Rochester mine (3), Nevada Packard (4), and Willard mine (5). The regional map base is derived from digital data obtained from U.S. Geological Survey digital data series: DDS-041 (Raines et al 1996).

directions (Erickson et al 2000; Ouyang et al 2003). In a mineral deposit, this may suggest preferred paths of metal introduction and redistribution and hence correspond to zones of anomalous enrichment or depletion. Details of variography analysis are discussed in later sections. The variogram maps are constructed to identify the spatial-anisotropy of the gold assay data and the directions of the strong anisotropy are identified as 'inherrent structural trends' of the Au-concentration data. The results are compared with the results of the visual analysis of GIS-derived contour maps as discussed earlier. These results are used in conjunction with the field observations of the authors to infer the location and orientation of structural features in the deposit that possibly guided fluids responsible for gold deposition and redistribution in this deposit.

The combination of the GIS and geostatistical analyses applied to the geochemical data to identify and map the structural elements in a mineral deposit is a novel approach that could be 
useful during mineral exploration from the early evaluation of prospects through advanced mine development.

\section{Study area}

The Florida Canyon gold deposit is a low-grade, low-sulfidation deposit located along the northwest margin of the Humboldt Range, Pershing County, Nevada (figure 1). From 1986 through 2006 gold was produced by open pit mining and cyanide leach extraction with total production amounting to 51.77 metric tons of $\mathrm{Au}$ at an average grade of $0.77 \mathrm{~g} / \mathrm{t}$ (Larsen 2007). Florida Canyon deposit is hosted by weakly metamorphosed sedimentary rocks of Grass Valley Formation (Triassic). Unlike other low-sulfidation epithermal deposits, the Florida Canyon deposit is not known to have association with any coeval igneous rocks (Samal and Fifarek 2007). Mineralization at the Florida Canyon deposit has some similarity with Carlin type deposits such as $\mathrm{Au}$ bearing pyrite and occurrences of jasperoid (Person et al 2008). However, Florida Canyon deposit occurs adjacent to a Humboldt House geothermal system (Samal et al 2005) which may be related to the genetic history of the deposit (Samal and Fifarek 2007).

Although gold mineralization is largely disseminated through weakly metamorphosed siltstones and sandstones of the Grass Valley Formation, the most intense mineralization and alteration is localized near the intersection of a north-trending, range-bounding fault that truncates the deposit on the west and the northeast-trending Madre shear zone on the north (Hastings et al 1988; Thomason 2002; Preuss et al 1997). Subsidiary faults associated with these trends are recognized in the mine area in addition to a subtle northwest structural grain that parallels prominent drainages in this region of the Humboldt range (Thomason 2002). However, the control on mineralization exerted by these subsidiary faults is not readily apparent in mine exposures.

All production to date has been from the oxidized top of the deposit. Pervasive alteration in the oxidized zone consists of widespread kaolinitehematite and localized bleached zones of quartzalunite-kaolinite. Stable isotope values for alunite indicate an origin from steam-heated, acidic oxidizing fluids that formed near the water table (Samal et al 2005; Samal and Fifarek 2006a). Weatheringrelated alteration and oxidation are present but their effects are difficult to distinguish from steamheated alteration and fracture filling. Cross-cutting relationships and ${ }^{40} \mathrm{Ar} /{ }^{39} \mathrm{Ar}$ dates clearly indicate that hematite and quartz-alunite-kaolinite assem- blages overprint quartz-adularia-sulfide stockwork zones and their silicified and illite-kaolinite altered host rocks. Accordingly, steam-heated alteration and oxidation are younger than the sulfide-forming hydrothermal event and were superimposed on sulfidic rock by a relative drop in the water table (Samal and Fifarek 2007).

Electrum and native gold are the principal ore minerals. In unoxidized rock, they occur as inclusions in quartz veins and pyrite, particularly the colloform banded variety. In oxidized rock, they are associated with vein quartz and hematite. Even though gold has been liberated from pyrite by oxidation, a supergene enrichment of gold has not been documented for the deposit.

\section{Variogram maps: An introduction}

The spatial continuity and underlying structure of a spatially autocorrelated variable in nature can be mathematically characterized using variogram functions. In this study, a set of gold assay values is analysed using variography. Gold concentration data used in this study is a spatially autocorrelated variable (i.e., values of a variable is compared with the values of the same variable to measure the spatial dependancy in space), and a regionalized variable (i.e., a variable whose values are distributed over space and meet the criteria of 'second-order stationarity', Isaaks and Srivastava 1989; Armstrong 1998). Spatial autocorrelation is also referred to as spatial dependency in space. The spatial structure (inherited spatial arrangement) of an autocorrelated variable can be modelled in several ways such as through the use of variograms, covariograms, correlograms and madograms (Pannatier 1996; Wackernagel 2003; Armstrong 1998).

In geostatistics, the variogram is the most commonly used tool for modelling spatial structure and is often known as a 'semivariogram' and noted as $\gamma(h)$. The semivariogram is calculated as half of the average squared difference between paired data values. The semivariogram is presented as:

$$
\gamma(h)=\frac{1}{2 N(h)} \sum_{i=1}^{N}\left[v\left(x_{i}\right)-v\left(x_{i}+h\right)\right]^{2}
$$

where $h$ is the lag distance (separation distance between sample pairs), $v\left(x_{i}\right)$ is the value of variable $x$ at location $i, v\left(x_{i}+h\right)$ is the value of $x$ at a distance $i+h, N$ is the number of pairs and $x$ is $\mathrm{Au}$ in this paper. The semivariogram is a line-graph of the variogram values, i.e., the average variances $\gamma(h)$ against distances between sample separation ( $h$ or lag). Semivariograms calculated along a particular direction (azimuth) 
from a geologically well constrained dataset are known as 'directional variograms'. Directional variograms are useful in modelling the spatial autocorrelation of a regionalized variable along specific directions (azimuths). The sample separation distance (lag) beyond which the variable behaves as a random variable is known as the range of a directional (or, omnidirectional) variogram. Hence, the range is representative of spatial continuity in that particular direction. In case of
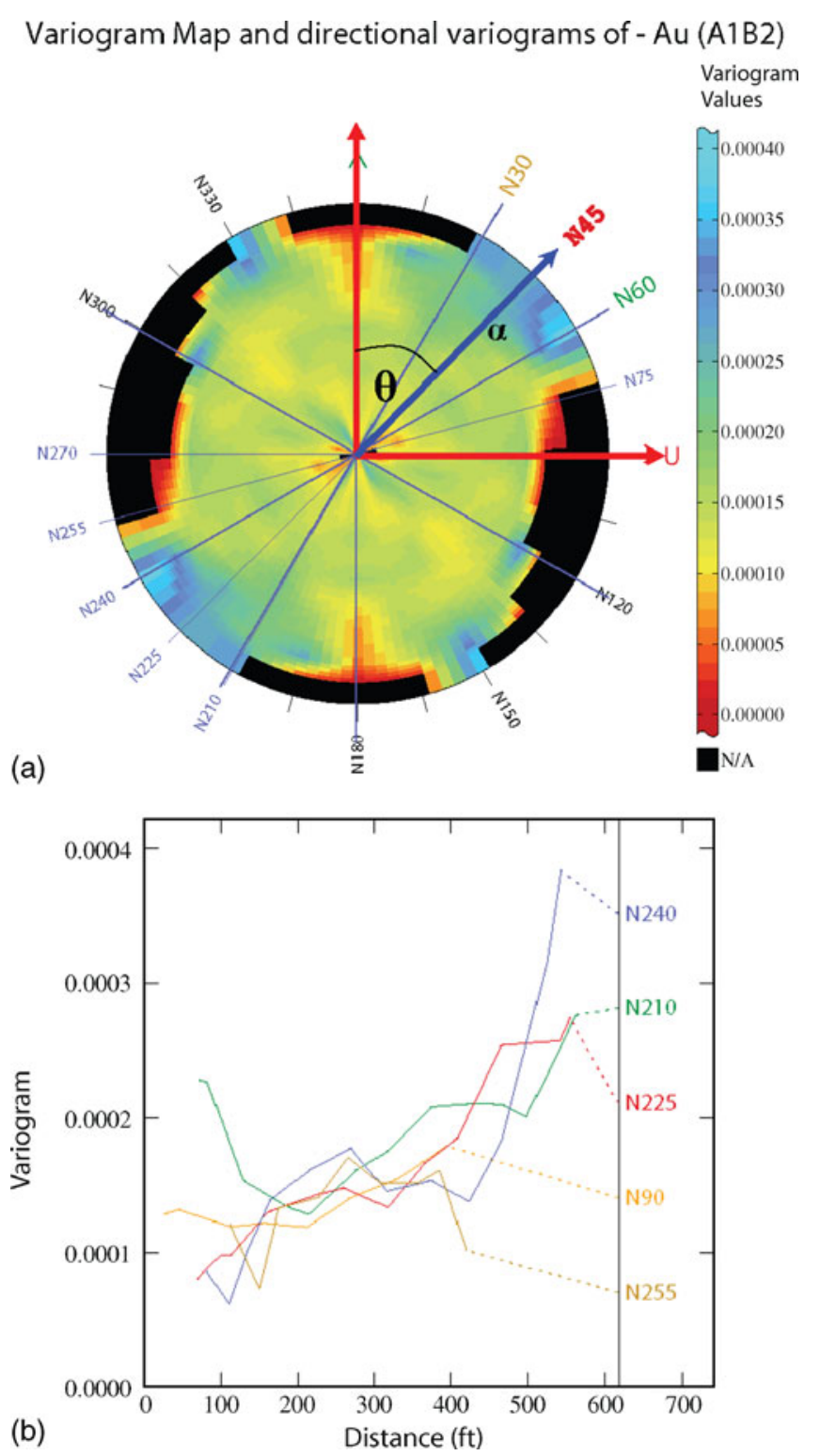

Figure 2. (a) Variogram map of $\mathrm{Au}$ concentrations for the area bounded by mine coordinates E51000 to E51500 and N49000 to N49500. (b) Variogram values plotted versus lag distance for selected prominent directions revealed by the variogram map (blue lines). The directions are N0, N30, N45, N60, and N120 (variogram values are the same in both directions along an azimuth. In this example, N45E is the dominant direction of the inferred structural trends for the chosen mine area. Refer the text for details. an anisotropic set of data, such as the Au assay values of a vein type gold deposit, the range of the variograms along the strike of the vein is larger than the range of variograms in the width direction.

The anisotropy of a three dimensional (3D) dataset can be modelled using variogram values calculated along all possible directions. To visualize changes in these values along multiple directions two dimensional (2D) variogram maps may be constructed, as illustrated in figure 2 for a subset of the Florida Canyon data. In a $2 \mathrm{D}$ variogram map, the semivariances calculated at different lag distances $(h)$ are represented as grid cells along multiple azimuths ( $\theta$ in figure $2 \mathrm{a}$ ) originating from a common point as seen in plan view. These grid cells are displayed in colour codes representing variation in semivariance. A grid cell in the variogram map represents semivariances, i.e., the average of variances for a group of paired data points that are aligned along an azimuth $(\theta)$ with angular tolerance of $\alpha$, i.e, $\theta \pm \alpha$, within the grid cell and at distances of separation between $i$ and $i+h$. The angle and the angular tolerance $(\theta \pm \alpha)$ is userdefined. The variogram map shown in figure 2 (a) is computed along 24 major directions at every $15^{\circ}$. The angular tolerance is $0^{\circ}$. The lag distance is $50 \mathrm{~m}$ and 10 lags are used for constructing this variogram map. It should be noted that the goal of this exercise is to identify the major direction of spatial anisotropy from the structure of the variogram map. The directional variograms are shown in figure 2(b). The variogram maps are a $2 \mathrm{D}$ representation of semivariances on a defined plane and can be derived for any direction in $3 \mathrm{D}$ space by defining the plane in any orientation.

\section{Use of variogram maps in geological interpretation of structural elements: A review}

Variogram maps have found a wide range of applicability in understanding spatial anisotropy in geosciences. For example, these maps were used by Drew et al (2003) to model the spatial continuity of water well yields associated with the fracture properties of the crystalline basement rocks in the Pinardville quadrangle, New Hampshire. They found that the spatial structure of water well yields were similar to the fracture patterns of the study area. Similar results were obtained in Loudoun County, Virginia, where field evidence of underlying geological structures was used to validate $2 \mathrm{D}$ variogram maps of water well yields (Sutphin et al 2000; Drew et al 2004). An excellent match between geological information of a complex carbonate reservoir and porosity variograms was 
found in the Eastern Province of Saudi Arabia (Sahin et al 1998). Similar geostatistical analyses related to geological features were published by Lin et al (2004) and Kumke et al (2005). Collectively, these studies suggest that variogram maps can provide information about underlying geologic structures.

Smith and Williams (1996) applied variography to model the spatial variability and structure of element concentrations at a mine waste site. A similar study accounted for the spatial variability of elements in a gold-silver deposit at Marrancos, Portugal (Reis et al 2004). In other applications, variogram models of various natural factors such as forest floor water content (WC), $\mathrm{pH}$, substrateinduced respiration (SIR, a measure of microbial biomass), and $\mathrm{N}$ mineralization, are used to infer major and minor spatial structures present in the data (Bruckner et al 1999). In essence, the use of variograms for identifying inherent structural patterns from spatially variable natural data is an established geostatistical technique and gaining popularity in variety of scientific research and applications.

\section{Dataset preparation and analytical procedures}

\subsection{Drill hole data}

Data analysis was performed on a spatially explicit dataset that consisted of gold assay and lithologic information for more than 3000 drill holes from the Florida Canyon deposit. The dataset consisted of 300,480 data points for which $\mathrm{x}-\mathrm{y}$ coordinates were calculated with reference to a mine grid and an elevation ( $\mathrm{z}$ ) calculated above mean sea level (msl).

\subsection{Oxidation surface}

The oxidized top of the deposit is distinguished by hematite and minor goethite and an absence of sulfides. Below a specific depth in each drill hole and over an interval of a few meters, the Fe-oxide/hydroxide minerals decrease and sulfide minerals increase until a sulfide-stable, hematitegoethite free zone is reached. To map the surface that defines the lower limit of complete oxidation (sulfide-absent), locations of the highest level of sulfides intersected by each drill hole were selected using a selection tool available in an industry standard exploration-mine development software package, Gemcom ${ }^{\circledR}$. These points were joined together using a triangulation technique, known as Laplace gridding technique (Gemcom 2006), to simulate this surface, herein referred to as the 'oxidation surface'. Laplace gridding uses a surface fitting technique for $3 \mathrm{D}$ data that is not susceptible to cluster or bull-eye effects unlike 3D surfaces generated by the inverse distance power technique. The Laplace gridding uses a smoothness factor (C) which allows the user to control the smoothness of the surface. If $\mathrm{C}$ is set to 0 , no smoothness occurs and the surface is created by joining all points. The result is a surface with the maximum irregularity that represents all actual data points but does not include estimates of points at unsampled locations. With increasing values of $\mathrm{C}$, the $\mathrm{Gemcom}^{\circledR}$ laplace gridding method uses an iterative process to progressively smoothen the surface, ultimately approaching a bi-cubic spline function. The surface generated using Gemcom ${ }^{\circledR}$ is accessed inside a GIS system for further analyses. The gradual changes in surface elevation is analysed using a terrain analysis function in GIS that expresses variations in the rate of change in slope to generate a 'slope derived surface' as seen in figure 3 .

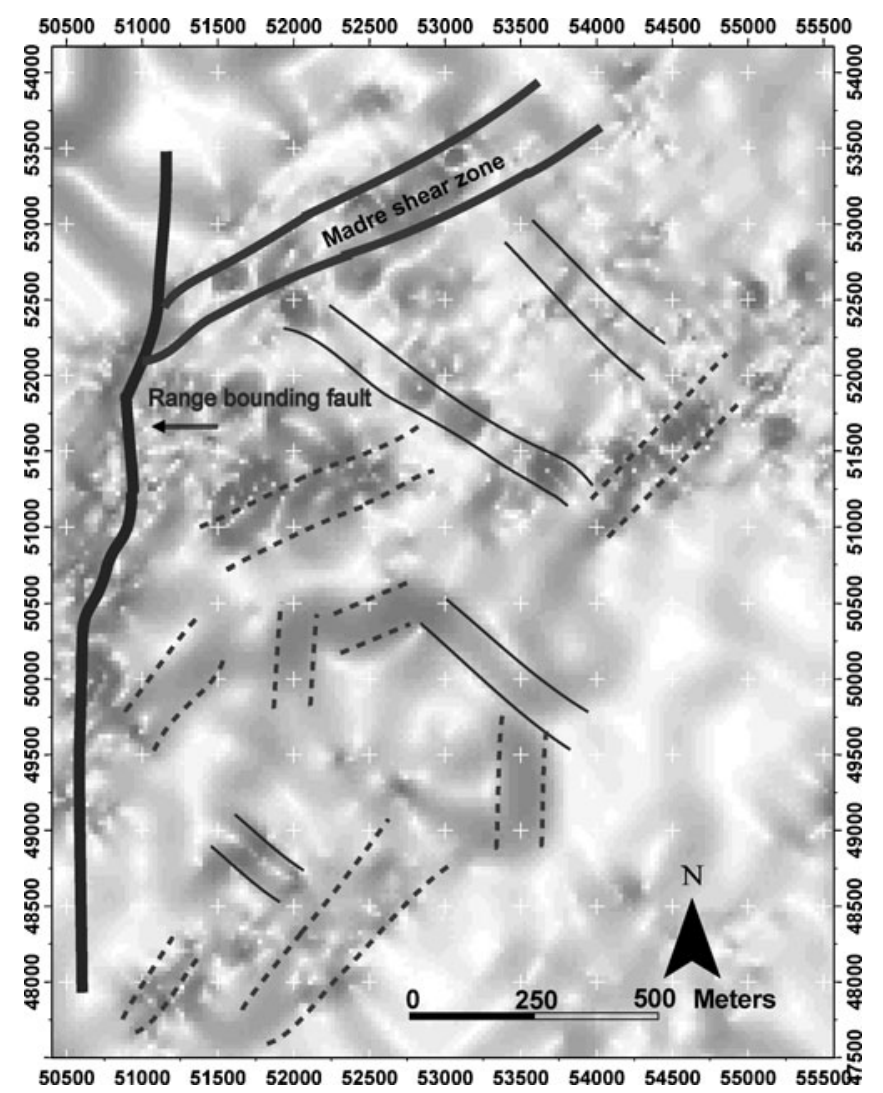

Figure 3. A slope-derived map of the surface representing the lower limit of oxidation (oxidation surface) at the Florida Canyon mine. Shades of gray express slope angle of the surface with darker shades equating to steeper slopes and lighter shades to flatter slopes. Pairs of dashed lines bound interpreted NE-trending linear features and pairs of solid blue lines bound NW-trending features, both of which suggest possible fault and shear zones. Solid lines denote the two major structures known from geological investigations, the range-bounding fault and Madre shear zone. 


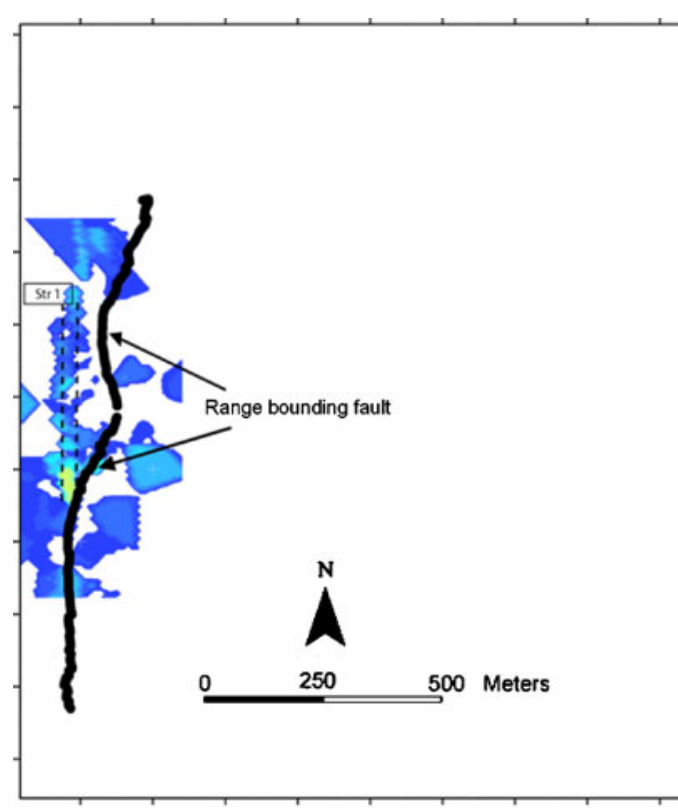

(a)

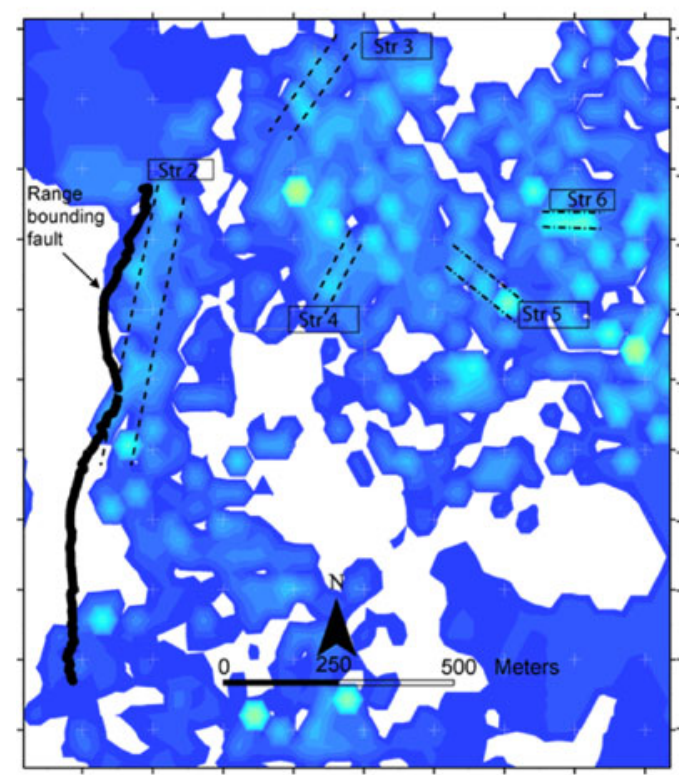

(c)
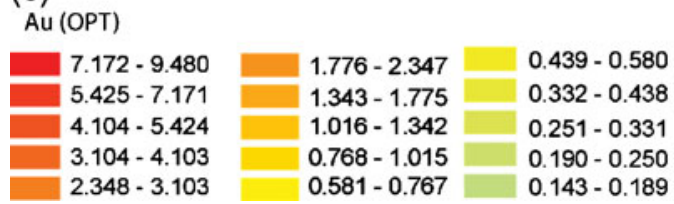

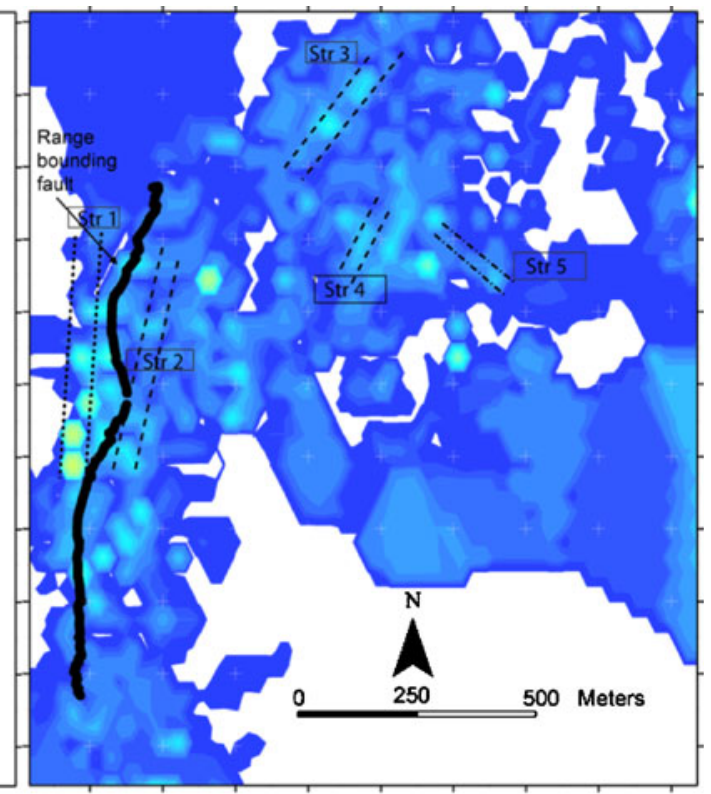

(b)

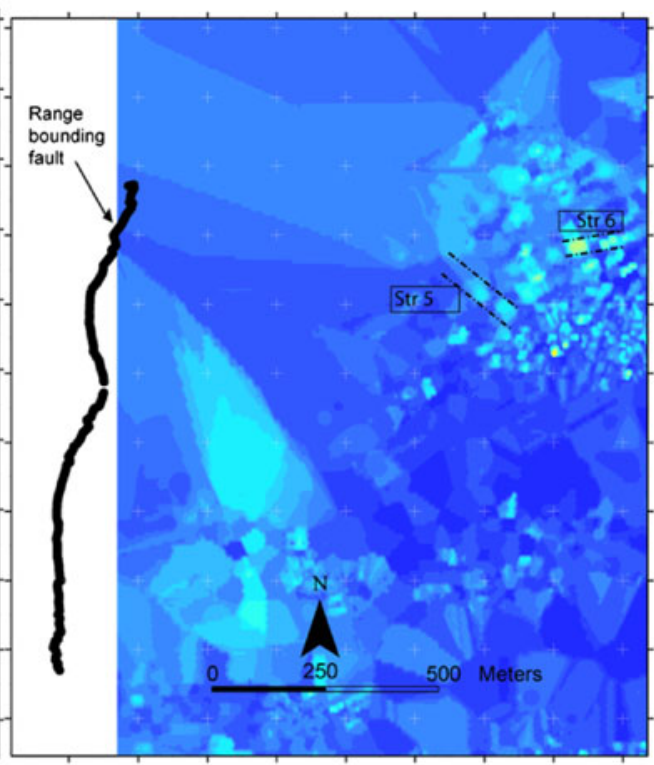

(d)

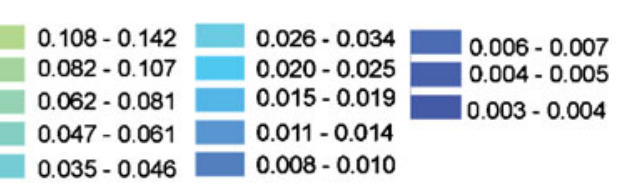

Figure 4. (a) Gold concentration contour map of the 3500-4000 ft (1066.8-1219.2 m) elevation interval. The interpreted structural element represents mineralization along the range-bounding fault (Str 1) that possibly intersects a NW-SE trend near its southern limit. Drill hole data are limited elsewhere at this interval. (b) Au concentration contour map of the 4000$4500 \mathrm{ft}$ (1219.2-1371.6 m) elevation interval. The contours of high Au-concentrations are located along the range-bounding fault and in a broad zone to the NE. The interpreted structures are Str 1, Str 2, Str 3, Str 4 and Str 5 . The Str 1 and Str 2 are along North-South to NNE-SSW trending range-bounding fault zone; the Str 3 and Str 4 are NE trending and Str 5 is NW trending. (c) Au concentration contour map of the 4500-5000 ft (1371.6-1524 m) elevation interval. Possible structural zones include Str 2, Str 3, Str 4, Str 5 and Str 6. The Str 2, Str 3, Str 4 and Str 5 are interpreted as continuing from the 4000-4500 ft (1219.2-1371.6 m) level. The Str 6 shows a small but strong EW trend. (d) Au concentration contour map of the 5000-5500 ft (1524-1776.4 m) elevation interval. Possible structures include NW-SE trending Str 5 and EW trending Str 6. Due to low-density of data at this level, spatial trends are not visible in other parts of the deposit. In all these maps, the blank (no color) area has very low density of low grade Au content $(<0.003$ opt) providing no usable information to detect spatial trends. 


\subsection{Mapping linear trends in gold concentration using contour maps}

Gold concentrations in the oxidized zone obtained from the drill hole data were converted into GISbased contour maps. Since the elevation of values ranged from 3500 to $6000 \mathrm{ft}$ (i.e., 1066.8 to $1828.8 \mathrm{~m}$ ), the 300,480 data points were subdivided by elevation into five subsets representing 500 vertical feet $(152.4 \mathrm{~m})$ each. Each of these subsets were then analysed independently to create four gold concentration contour maps, or one each for the elevation ranges, 3500-4000 ft (i.e., 1066.8-1219.2 m), 4000-4500 ft (i.e., 1219.2$1371.6 \mathrm{~m}), 4500-5000 \mathrm{ft}$ (i.e., $1371.6-1524 \mathrm{~m}$ ), 5000-5500 ft (i.e., $1524-1776.4 \mathrm{~m}$ ) and 5500$6000 \mathrm{ft}$ (i.e., $1776.4-1828.8 \mathrm{~m}$ ).

For each drill hole, the data point closest to the mid-point of each elevation range was selected to represent the location in $\mathrm{x}$ and $\mathrm{y}$ in local coordinates, of that particular drill hole data in a GIS layer. The gold assay values, reported in ounces per ton (opt, 1 opt $=28.34952312$ grams per ton, gpt), were averaged over the elevation range and attributed to this point. The inverse-distance-square (IDS) interpolation technique, available within the standard GIS software package ArcGIS 9.1 was utilized to interpolate and contour the gold values (figure $4 \mathrm{a}, \mathrm{b}, \mathrm{c}$ and $\mathrm{d}$ ). The IDS technique is preferred over kriging, because the surface generated using the IDS technique shows the change in dip and elevation of the surfaces more prominently as compared to the ones generated using kriging.

The concentration contour interval was determined by a natural break classification, known as the Jenk's optimization technique, which resulted in 15 divisions between the lowest (0.0001 opt, i.e., 0.00235 gpt) and highest (9.480 opt, i.e., $268.75348 \mathrm{gpt}$ ) gold values. The Jenk's optimization algorithm calculates groupings of data values based on the smallest possible total error within the class. Once the maps were created, linear trends of higher gold concentrations were interpreted by visual inspection (shown as dotted lines in figure $4 \mathrm{a}, \mathrm{b}, \mathrm{c}$ and $\mathrm{d}$ ). The identified linear trends or linear structural features (Str x) are designated as Str 1, Str 2, etc. Only the major trends, those repeat in two or more levels are considered in this paper.

First, these interpreted structural features were verified in the areas of known major structures. As it can be seen in figure $4(\mathrm{a}, \mathrm{b}$ and $\mathrm{c})$, the $\operatorname{Str} 1$ and Str 2 are along the known major fault zone (range-bounding fault). Also, Str 3 was found to be approximately parallel to the Madre shear zone. The other identified linear trends (Str 4, Str 5, Str 6) are interpreted as locations of fracture, fault or shear zones. Structures 3, 4 and 5 seem to be prominent and continuing up to $5000 \mathrm{ft}(1524 \mathrm{~m})$ deep. Figure $4(\mathrm{~d})$ does not show any evidence of structural elements in the western and southern sides, because of low density of data at this depth.

The data used to create the above-mentioned maps were combined to create a contour map of $\mathrm{Au}$ concentrations for the entire 3500 to $5500 \mathrm{ft}$ $(1066.8$ to $1776.4 \mathrm{~m})$ interval of the deposit (figure 5). Linear trends interpreted as fault or shear zones (Str $\mathrm{x}$ designation) are identified on the map. Repetition of these linear trends at multiple map levels strengthens the probability that they represent actual structural elements.

\subsection{Variogram map analyses}

To confirm the linear trends observed in the contour maps, the drill hole data were used to construct variogram maps which provide directions of possible structural control of mineralization and

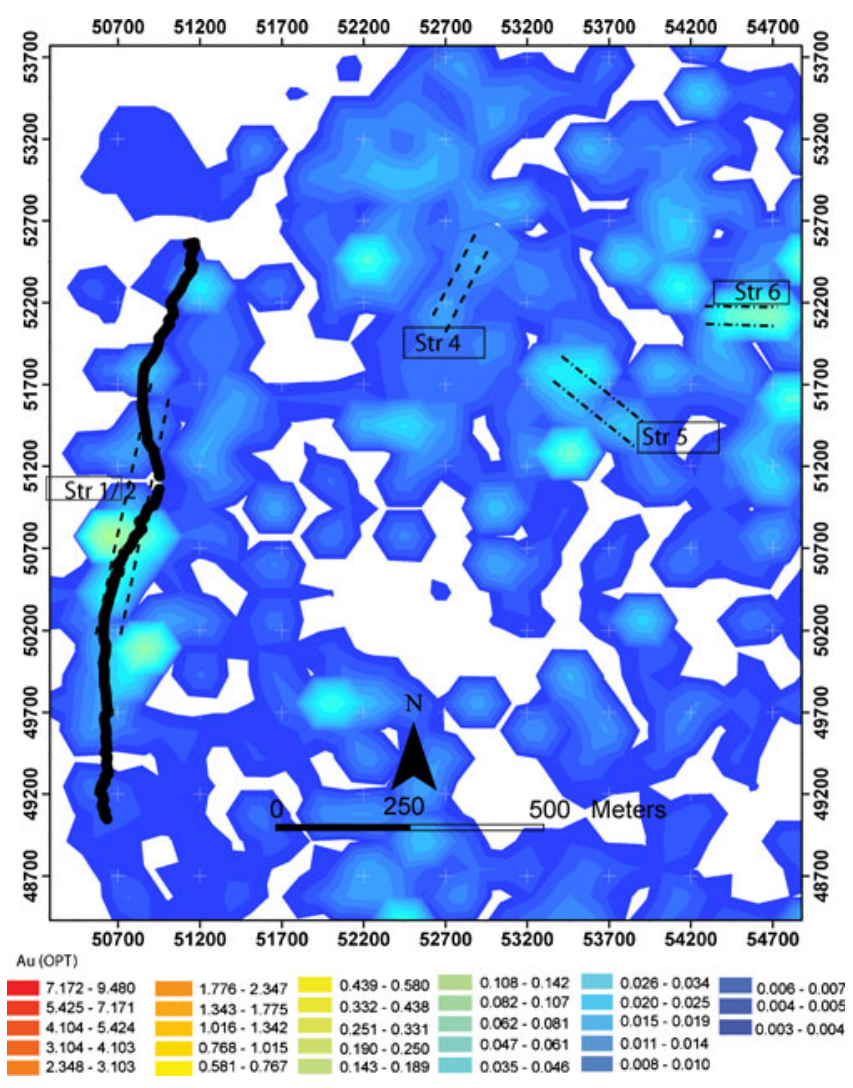

Figure 5. Au concentration contour map of the 3500-5500 ft (1066.8-1776.4 m) elevation interval. This map was created using a combined dataset between $1066.8 \mathrm{~m}$ (i.e., $3500 \mathrm{ft}$ ) and $1776.4 \mathrm{~m}$ (i.e., $5500 \mathrm{ft}$ ). The interpreted shear zones appear to be those that extend vertically through most of the deposit. Those repeated at other levels include Str 1 and/or Str 2, shown as $\operatorname{Str} 1 / 2, \operatorname{Str} 4$, Str 5 and $\operatorname{Str} 6$. The Str $1 / 2$ may be due to the combined effect of Str 1 and Str 2. The blank (no color) area has very low density of low grade Au $(<0.003$ opt $)$ data with no spatial trend. 
Table 1. Reference plan parameters used to create variogram maps using ISATIS ${ }^{\circledR}$ software.

\begin{tabular}{lc}
\hline Plane of variogram map & X-Y (east-north) plane \\
Rotation & No \\
Variogram map parameters: & 12 \\
Number of directions & 10 \\
Number of lags & $100 \mathrm{ft}(30.48 \mathrm{~m})$ \\
Lag value & 0 \\
Angular tolerance (number of sectors) & 1 \\
Tolerance on distance (number of lags) & 1 \\
Minimum number of pairs per cell & Not required \\
Slice height & Not required \\
Slice X reference & Not required \\
Slice Y reference & Not required \\
Slice Z reference & $0 \mathrm{ft}$ \\
Slice minimum lag value & \\
\hline
\end{tabular}

directions of best continuity of grade. As stated earlier, structural features such as faults and fractures influence fluid flow and element concentrations along them. Therefore, gold concentrations aligned along these structural features would show a stronger spatial correlation for a longer distance in the direction of the structures than in other directions. Under these circumstances semivariance may increase slowly over relatively longer distances and have larger ranges compared to other directions. This phenomenon is shown in figure 2 where semivariances along the N45-N225 azimuth show stronger spatial correlation and a larger range compared to other directions. Hence, as discussed in section 4 , for that subset of data and geographical area it is interpreted that the orientation of the most prominent structural element that guided mineralizing fluids is $\mathrm{N} 45-\mathrm{N} 225$.

The first step in the variogram map analysis was the identification of outliers of gold concentration. Histograms suggest that gold values above 2 opt belong to a statistically different population and constitute less than $2 \%$ of the total data. Therefore, only data points with gold values between 0 and 2 opt were selected for analysis. Further, in order to avoid excessive spatial bias due to paucity of data, variogram maps were generated only for the 4500 to $5000 \mathrm{ft}$ (i.e., 1371.6-1524 m) elevation interval because it contained abundant data over most of the mineralized area in Grass Valley formation. These data points were subdivided geographically into forty-eight $500 \times 500 \mathrm{ft}(152.4 \times 152.4 \mathrm{~m})$ grids. Each grid was labeled as $\mathrm{A}_{\mathrm{x}} \mathrm{B}_{\mathrm{y}}$, where ' $\mathrm{x}$ ' represents a grid number eastward and ' $y$ ' represents a grid number northward from an arbitrary starting point. A total of 48 grids, from $\mathrm{A}_{1} \mathrm{~B}_{2}$ to $\mathrm{A}_{7} \mathrm{~B}_{9}$, i.e., in the area bound by N49000-E51000 and N53000E54000, were considered for variogram analysis; other grids had inadequate data for generating variogram maps. Due to non-uniform distribution of data and insufficiency of data the variogram maps for the grids outside the above-mentioned area could produce misleading results; hence these grids were excluded from variogram-map analyses. The selection of data was done using a data filtering tool available within the ISATIS ${ }^{\circledR}$ geostatistical software that was used for this analysis. The parameters used to create each of the variogram maps are reported in table 1.

\section{Results}

\subsection{Oxidation surface}

The oxidation surface dips gently westward across most of the mine area but changes to steeper dips along the west side where the surface and deposit are truncated by a north-south rangebounding fault (figure 3). However, along certain linear trends, the oxidation surface rapidly changes dip and plunge before returning to its general gradient. These linear trends are interpreted as the loci of faults and shear zones where induced secondary permeability allowed downward percolating oxidizing fluids to penetrate to greater depths. The trends indicated on the slope-derived map of figure 3 are visual estimates of linear zones of rapid slope change of the oxidation surface. Interpreted linear trends of NE, NW and, to a lesser extent, $\mathrm{N}-\mathrm{S}$ trending zones are shown on the map relative to major known structures, specifically the range-bounding fault and Madre shear (figure 3).

\subsection{Contour maps of gold concentrations}

On the 3500-4000 ft interval level (i.e., 1066.8$1219.2 \mathrm{~m}$ ) map of gold concentrations at the deepest levels of the open pit mine, high values are 
generally aligned along a broad N-S zone parallel to the range-bounding fault, although drill hole data are generally sparse and restricted to the west side (Str 1) of the deposit through this interval (figure 4a). At the next highest level at 4000$4500 \mathrm{ft}$ interval (i.e., $1219.2-1371.6 \mathrm{~m}$ ), the contour map shows a repeat of the same N-S trend (Str 1), labelled SZ1, a subparallel NS trend (Str 2) and broad NE-trending zone (Str 3) of gold enrichment that parallels the Midas shear located along the northern limit of the zone (figure 4b). Within this broad zone, the other NE trending linear feature (Str 4) and NW trending Str 5 are suggested by the alignment of relatively high grade zones. Some of these linear features appear to extend upward to the 4500-5000 ft (i.e., 1371.6-1524 m) level interval, where they are accompanied by additional zones of enrichment in the NE part of the deposit (figure 4c). Data are again sparse at $5000-5500 \mathrm{ft}$ interval level (i.e., 1524-1776.4 m), although short linear zones trending NE and NW trend are pronounced in the NE section of the deposit (figure 4d). Too few data points were available for generating an $\mathrm{Au}$ contour map at the highest level, i.e., at $5500-6000 \mathrm{ft}$ (i.e., 1776.4 to $1828.8 \mathrm{~m}$ ). When the data are combined into a $2000 \mathrm{ft}$, i.e., $609.6 \mathrm{~m}$ elevation interval, from 3500 to $5500 \mathrm{ft}$ (i.e., $1066.8-1776.4 \mathrm{~m} \mathrm{msl}$ ) the location and azimuth of the most through-going linears are revealed as illustrated in figure 5. Collectively, the NE-trending linear trending zones appear to be the most prominent, followed by NW-trending linear zones, and then EW-trending linear zones (away from the range-bounding fault).

\subsection{Interpretation of variogram maps of $A u$}

Because gold concentrations are often controlled by fault and shear zones, it is justified to hypothesize that semivariances along structural trends will have the largest range due to a stronger spatial correlation in these directions; which is represented by slower rise in semivariances for longer distance in variogram maps. In 42 out of the 48 grids considered in developing the variogram map for the 4000-4500 ft $(1219.2-1371.6 \mathrm{~m})$ interval, the largest ranges of semivariances occur along

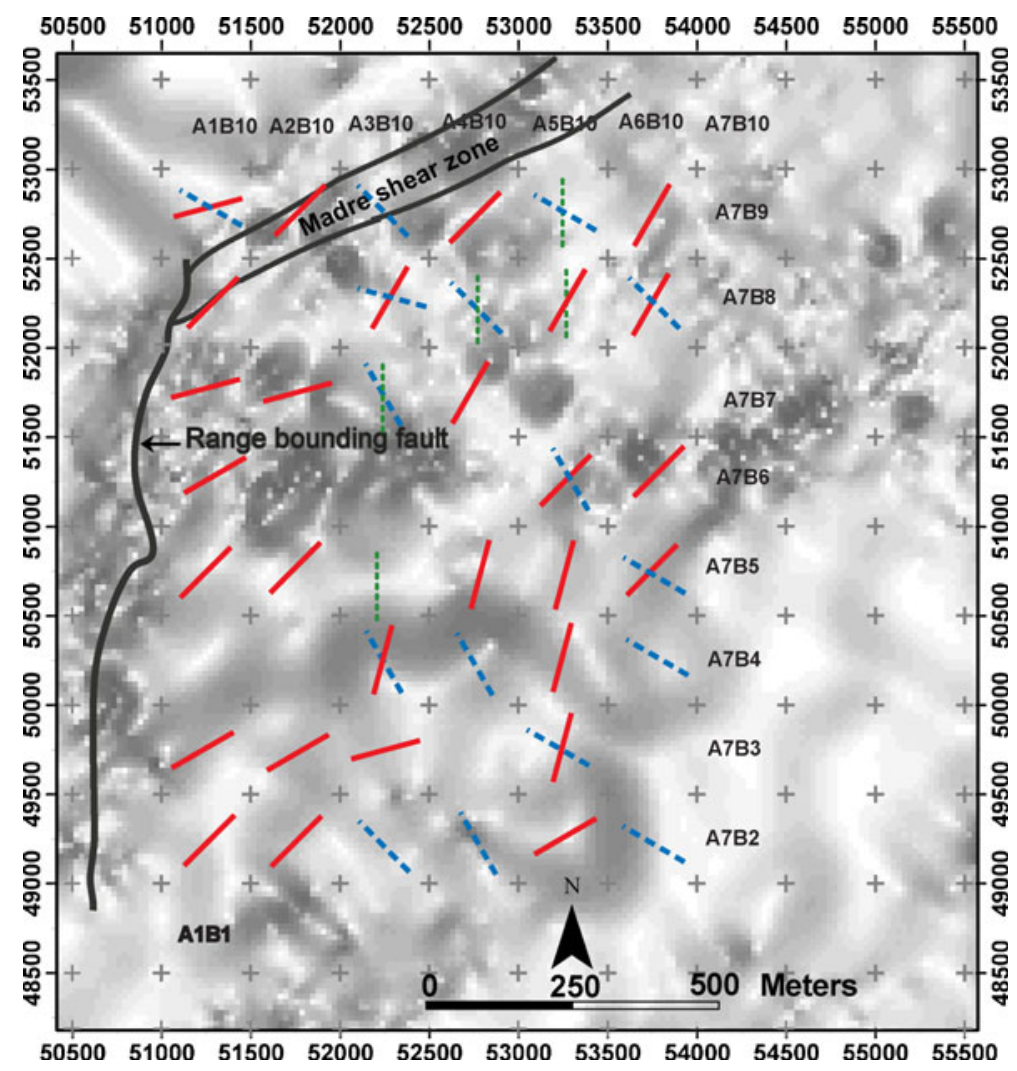

Figure 6. Prominent linear trends derived from variogram maps of $500 \times 500 \mathrm{ft}(15.4 \times 152.4 \mathrm{~m})$ grids at the $4000-4500 \mathrm{ft}$ $(1219.2-1371.6 \mathrm{~m})$ elevation level superimposed over the oxidation surface. Solid (red) lines represent NE-trends, dashed (blue) lines NW-trends, and dotted (green) lines N-S trends. For explanation purposes, the variogram map for the area bounded by E51000 to E51500 and N49000 to N49500 (A1B2) is shown in figure 2. The variogram maps for all other entire deposit were calculated for 48 grids (each $500 \times 500 \mathrm{ft}$ and bounded by grey coloured cross signs $(+$ ). As discussed in section 5.4 , these 48 grids are labeled as AxBy, where ' $\mathrm{x}$ ' represents a grid number eastward and ' $y$ ' represents a grid number northward from an arbitrary starting point. A total of 48 grids, from A1B2 to A7B9 are used. 
northeast (N30 to N60) and northwest (N300N345) directions (figure 6). North-south directions are identified only in the central region of figure 6 , although the absence of these trends in the southern part of the deposit may be attributable to the lower density of data in that area.

Overall, the trends predicted by variography closely match those interpreted from the gold contour maps and oxidation surface map. Two of the trends match those of the two known goldbearing structures in the deposit, the north-south range-bounding fault and northeast Midas shear zone. This concurrence of results by various methods and at different scales affirms the hypothesis that the variogram directions with larger ranges and greater spatial correlation represent structural trends which can be mineralized faults and shear zones.

\section{Discussion and conclusions}

Although it was recognized that gold was concentrated along northeast and north-south sets of structures in the Florida Canyon deposit (Hastings et al 1988; Thomason 2002), the presence and role of northwest structures in focusing ore-fluids was more conjectural. The analysis of the gold contour maps and variogram maps provided by this study clearly identifies the two major ore controlling structures in the deposit and their trends, the north-south range-bounding fault and northeast Midas shear zone. However, away from these two structural zones the results also highlight the importance of the northwest set of structures as an ore control, particularly at higher levels and in the NE area of the deposit. Additionally, intersections of northwest and northeast structures appear to have localized some gold anomalies. These conclusions provide important guides for the further exploration of the Florida Canyon mine area and for similar deposits along the western foothills of the Humboldt Range.

Gold was initially introduced preferentially along structures during the formation of quartz-adulariasulfide stock-work and veins. Downward percolating oxidizing fluids of steam-heated origin and later of weathering origin overprinted this mineralization along the same permeable structural conduits that guided hypogene mineralization, as implied by the coincidence of linear trends on the oxidation surface and gold contour maps. These fluids liberated gold encapsulated in sulfides and to some extent in quartz and likely redistributed the gold at least at a local scale. Consequently, the patterns of gold concentrations revealed by the contour maps and variogram maps represent the time integrated effects of both hydrothermal events.
In a more regional context, the northweststriking faults are subparallel to a prominent set of drainages in the Humboldt Range surrounding the mine area. Similarly, the northeast-trending Midas shear zone is part of a regional lineament marked by the common orientation of joints, faults and veins (Hastings et al 1988). Sparse cross-cutting relations observed around the mine area suggest the northwest set of faults post-date the northeast structures and both are clearly offset by the range-bounding fault and subsidiary structures. The range-bounding, normal fault acted as the major conduit for the episodic upwelling of fluids over the last $5 \mathrm{Ma}$ (Samal and Fifarek 2006b). Yet displacements on the fault during the same time interval suggest that the hangingwall block, now buried by $\geq 305 \mathrm{~m}$ of valley-fill sediments, may be mineralized directly down dip of the Florida Canyon deposit. If so, the structural model for the Florida Canyon mineralization proposed herein may prove effective in the exploration of such a blind target.

The results of this study demonstrate the advantages of using GIS-based geochemical maps in conjunction with geostatistical analysis to recognize ore controlling fault sets and their relative importance in large, disseminated, low-grade deposits where ore controlling structures are subtly expressed. Such a methodology can be effectively employed in the ongoing exploration of a mine area, search for blind extensions of known deposits, and in the discovery of disseminated gold deposits in similar tectonic settings. Future research along this direction may lead to important refinements of the method and applications to other deposit types.

\section{Acknowledgements}

The authors thank Mr. Robert Thomason, Mr. Richard Larsen and management of the Florida Canyon Mining Company for their cooperation in supplying the necessary information, data and logistical support to carry out this study as part of a comprehensive research project on the deposit. Financial support was provided by the Florida Canyon Mining Co, United States Geological Survey, and a subcontract to a Department of Energy - National Renewable Research Laboratory (DOE-NREL grant administered by the University of Nevada - Reno).

\section{References}

Adams D 2006 Geochemical Sampling and Geostatistics Notes, Delta Mine Training Center; http://www. dmtcalaska.org/course_dev/explogeo/class12/notes12. html (accessed December 10, 2006). 
Armstrong M 1998 Basic Linear Geostatistics (Berlin: Springer), pp. 18-19.

Bruckner A, Kandelerb E and Kampichlerc C 1999 Plotscale spatial patterns of soil water content, $\mathrm{pH}$, substrateinduced respiration and $\mathrm{N}$ mineralization in a temperate coniferous forest; Geoderma 93(3-4) 207-223.

Drew L J, Karlinger M R, Schuenemeyer J H and Armstrong T R 2003 Hydrogeologic significance of the association between well-yield variography and bedrock geologic structures, Pinardville Quadrangle, New Hampshire; Natural Resour. Res. 12(1) 79-91.

Drew L J, Southworth S, Sutphin D M, Rubis G A, Schuenemeyer J H and Burton W C 2004 Validation of the relation between structural patterns in fractured bedrock and structural information interpreted from 2D-variogram maps of water-well yields in Loudoun County, Virginia; Natural Resour. Res. 13(4) 255-264.

Erickson T A, Williams M W and Sommerfeld RA 2000 Spatial statistics of snowmelt; In: Computational methods in water resources (eds) Bentley L R, Sykes J F, Brebbia C A, Gray W G, Pinder G F (Rotterdam: Balkema) 2 1147-1152.

GEMCOM 2006 Help file, Gemcom Software, Vancouver, Canada.

Harris J R, Grunsky E C and Wilkinson L 1997 Developments in the effective use and interpretation of lithogeochemistry in regional exploration programs: Application of GIS technology, In: Proceedings of Exploration 97: Fourth Decennial International Conference on Mineral Exploration (ed.) Gubins A G, Prospectors \& Developers Association of Canada, pp. 285-292.

Hastings J S, Burkhart T H and Richardson R E 1988 Geology of the Florida Canyon gold deposit, Pershing County, Nevada; In: Bulk Mineable Precious Metal Deposits of the Western United States, Symposium Proceedings (eds) Schafer R W, Cooper J J and Vikre P G, Geological Society of Nevada, pp. 433-452.

Isaaks E H and Srivastava R M 1989 An Introduction to Applied Geostatistics (New York: Oxford University Press) $561 \mathrm{pp}$

Kumke T, Schoonderwaldt A and Kienel U 2005 Spatial variability of sedimentological properties in a large Siberian lake; Aquatic Sci. 67 86-96.

Larsen R 2007 Personal communication regarding the mining operations at Florida Canyon Mines.

Lin Y B, Tan Y C, Liu C W, Lin Y P and Hung C J 2004 Geostatistical method to delineate anomalies of multiscale spatial variation in hydrogeological changes due to the ChiChi earthquake in the ChouShui River alluvial fan in Taiwan; Environ. Geol. 47 102-118.

McClenaghan M B, Thorleifson L H and DiLabio R N W 1997 Till geochemical and indicator mineral methods in mineral exploration; In: Proceedings of Exploration 97: Fourth Decennial International Conference on Mineral Exploration, (ed.) Gubins A G, Prospectors \& Developers Association of Canada, pp. 233-248.

Ouyang Y, Nkedi K P, Mansell R S and Ren J Y 2003 Spatial distribution of DDT in sediments from estuarine rivers of central Florida; J. Environ. Qual. 32(5) 1710-1716.

Pannatier Y 1996 VARIOWIN: Software for Spatial Data Analysis in 2D (New York, NY: Springer-Verlag) ISBN 0-387-94679-9.

Person G et al 2008 Hydrologic models of modern and fossil geothermal systems in the Great Basin: Genetic implications for epithermal $\mathrm{Au}-\mathrm{Ag}$ and Carlin-type gold deposits; Geosphere 4(5) 888-917; doi: 10.1130/ GES00150.1.

Preuss N E, Fifarek R H and Thomason R E 1997 Hydrothermal and vapor-related alteration at the Florida Canyon epithermal gold deposit, Pershing County, Nevada in Abstracts with Programs; Geol. Soc. Am. 29(6) 207.

Raines G L, Sawatzky D L and Conners K K 1996 Great basin geoscience data base [computer file], United States Geological Survey digital data series: DDS-041.

Reis A P, Sousa A J, Ferreira da Silva E, Patinha C and Fonseca E C 2004 Combining multiple correspondence analysis with factorial kriging analysis for geochemical mapping of the gold-silver deposit at Marrancos (Portugal); Appl. Geochem. 19(4) 623-631.

Sahin A, Ghori S G, Ali A Z, El-Sahn H F, Hassan H M and Al-Sanounah A 1998 Geological controls of variograms in a complex carbonate reservoir, eastern province, Saudi Arabia; Math. Geol. 30(3) 309-322.

Samal A R and Fifarek R H 2006a Modeling structural control of gold mineralization at the Florida Canyon epithermal gold deposit, Nevada: A 3-D GIS approach; Geol. Soc. Am. Abstr. with Programs 38(7) 372.

Samal A R and Fifarek R H 2006b Geological evolution of the Florida Canyon epithermal gold deposit, Nevada; In: The Power of Mining: Energy's Influence, 2007 SME Annual Meeting ES Exhibit and Colorado Mining Association 109th National Western Mining Conference, Denver, USA, pp. 60.

Samal A R and Fifarek R H 2007 Origin of the amagmatic low-sulfidation epithermal Florida Canyon $\mathrm{Au}-\mathrm{Ag}$ deposit, Pershing County, Nevada; Geol. Soc. Am. Abstr. with Programs 39(6) 606.

Samal A R, Fifarek R H and Thomason Robert E 2005 Steam-heated alteration at the Florida Canyon epithermal gold deposit, Nevada: Assemblages, timing and possible fluid sources; Geol. Soc. Am. Abstr. with Programs 37(7) 420, GSA 2005 Annual Meeting.

Smith M L and Williams R E 1996 Examination of methods for evaluating remining a mine waste site. Part I. Geostatistical characterization methodology; Engg. Geol. 43 $11-21$.

Sutphin D M, Drew L J, Schuenemeyer J H and Burton W C 2000 Characteristics of water-well yields in the Blue Ridge of Loudoun County, Virginia; Open-File Report 00-280, U.S. Geological Survey.

Thomason R E 2002 Geology and mineralization of the Florida Canyon Mine, Pershing County, Nevada; In: Precious metal deposits of the Humboldt Range: New discoveries in an old district, (ed.) Wendt C; Geol. Soc. Nevada, Spec. Publ. 36192.

Turner D D 1997 Predictive GIS model for sediment-hosted gold deposits, north-central Nevada, U.S.A.; In: Proceedings of Exploration 97: Fourth Decennial International Conference on Mineral Exploration, (ed.) Gubins A G; Prospectors \& Developers Association of Canada, pp. $115-126$.

Wackernagel Hans 2003 Multivariate Geostatistics (3rd edn.) Springer.

Yager D B and Folger H W 2003 Map showing copper concentrations from stream sediments and soils throughout the Humboldt river basin and surrounding areas, northern Nevada; U.S. Geological Survey miscellaneous field studies map mf-2407, e version 1.0. 